\title{
Los actos unilaterales de los Estados como fuente formal del derecho internacional público
}

\author{
Francisco Peña Silva*
}

\begin{abstract}
RESUMEN
El trabajo tiene por finalidad realizar una delimitación conceptual de los actos unilaterales de los Estados como fuente del derecho internacional público, a partir de la evolución histórica de su tratamiento por la doctrina y jurisprudencia internacional. A partir de ello, el autor realiza un estudio acerca de sus requisitos de validez y efectos.
\end{abstract}

Fuentes del derecho internacional público - actos unilaterales de los Estados - aquiescencia

\section{The unilateral acts of States as a formal sources of public international law}

\begin{abstract}
The purpose of the work is to make a conceptual delimitation of unilateral acts of States as a source of public international law, based on the historical evolution of its treatment by international doctrine and jurisprudence. From this, the autor make a study about their validity requirements and effects.
\end{abstract}

Sources of public international law - unilateral acts of States - acquiescence

* Licenciado en Derecho, Universidad Marítima, Chile. Magíster en Derecho, Pontificia Universidad Católica de Valparaíso. Profesor de Derecho Internacional Público, Pontificia Universidad Católica de Valparaíso. Correo electrónico: francisco.pena@pucv.cl.

Todas las traducciones son del autor. Agradezco los comentarios de los profesores Eduardo Aldunate, Octavio Ansaldi y María Soledad Pardo, y del Sr. Sebastián Chandía.

Artículo recibido el 28.4.2019 y aceptado para su publicación el 6.3.2020. 


\section{INTRODUCCIÓN}

$\mathrm{E}$ 1 objeto de la investigación es realizar un análisis del estado actual de la teoría general de los actos unilaterales en el derecho internacional público y determinar específicamente las hipótesis en que estos pueden producir efectos jurídicos y considerarse como una fuente formal del derecho internacional público. Se trata de un tema que en la doctrina internacional presenta varias controversias, incluso respecto de su función normativa, debido a la existencia de una diversidad en las formas en que dichos actos se manifiestan en el ámbito internacional. Por su parte, la doctrina nacional no se ha hecho cargo del tema con la profundidad necesaria ${ }^{1}$, lo que se refleja en la falta de consideración de la teoría general de los actos unilaterales en la praxis de los órganos internos del Estado de Chile. En efecto, la determinación de las condiciones en que los comportamientos de los órganos nacionales son idóneos para construir una regla de derecho internacional, pasa por el análisis del tema objeto de la investigación.

Frente a la diversidad de formas, y de posturas existentes respecto del tema, el presente artículo demostrará que es posible establecer criterios que permitan determinar bajo qué condiciones los actos unilaterales de carácter estatal producen efectos jurídicos, y por tanto, pueden ser considerados como fuente formal del derecho internacional público. La elaboración de dichos criterios tomará en cuenta, cuando ello sea pertinente, determinadas situaciones que han tenido alguna vinculación con la actividad unilateral de la República de Chile.

Con miras a dicho objetivo el trabajo se divide en dos partes. En primer lugar existe un acápite relativo a las nociones generales del tema, el que se encuentra constituido por un estudio acerca de la evolución histórica del tratamiento que han dado la doctrina, jurisprudencia e institucionalidad internacional acerca de los actos unilaterales de los Estados, y por una delimitación de su concepto. La segunda parte del trabajo se aboca al estudio de los requisitos de validez y efectos de los actos unilaterales.

\section{Nociones Generales}

\section{Evolución histórica del tratamiento de los actos unilaterales en el derecho internacional público}

La doctrina clásica se ocupó del tema de los actos unilaterales de los Estados a partir de la figura de la promesa, negando su carácter obligatorio en cuanto acto unilateral $^{2}$. Esta posición doctrinal resulta muy curiosa, sobre todo teniendo en cuenta que el elemento material de la costumbre internacional se forma a partir de la repetición de

${ }^{1}$ Una monografía que versa exclusivamente referente al tema corresponde a Rossel, 2007, pp. 589608. Un tratamiento muy general del tema en BenAdAVA, 2004, pp. 73-76; Llanos, 2009, pp. 587-595; VARGAS, 2017, pp. 108-112.

${ }^{2}$ Sicault, 1979 , p. 636. 
actos de carácter unilateral. En efecto, la costumbre ha tenido un rol considerable en la formación del derecho internacional, ya que este nace en el momento de la aparición de las primeras reglas consuetudinarias en el ámbito de las relaciones diplomáticas, de la guerra y de la navegación ${ }^{3}$.

La situación descrita se debió a tres motivos: en primer lugar, por el hecho que para gran parte de la doctrina de la época el acto unilateral era propio del derecho interno de los Estados, a diferencia de lo que ocurre con el acto convencional que es propio del ámbito internacional. Por tanto, la doctrina internacionalista no tenía interés en su estudio. En segundo lugar, la mayoría de los supuestos actos unilaterales de los Estados se encuentran vinculados a procedimientos de carácter convencional. Y, en tercer lugar, porque los Estados al no ejercer, en principio, autoridad los unos sobre los otros, no pueden crear efectos jurídicos con sus actos ${ }^{4}$.

Recién en 1933 es posible encontrar el primer hito jurisprudencial respecto de los actos unilaterales, específicamente el fallo del "estatuto jurídico de Groenlandia Oriental” de la Corte Permanente de Justicia Internacional (CPJI). Este caso se resuelve fundamentalmente a partir de la declaración realizada en 1919 por el ministro de Relaciones Exteriores de Noruega, Ihlen, en relación con la cuestión de la soberanía danesa sobre Groenlandia. En dicha declaración, el funcionario noruego expresa que su gobierno no opondría ningún obstáculo concerniente a ese asunto, a partir de una consulta realizada por el gobierno de Dinamarca.

La cuestión comienza en 1931 con un requerimiento interpuesto por el reino de Dinamarca en contra del reino de Noruega, debido a que este ocupó ciertos territorios de Groenlandia Oriental. La CPJI, tomando como base la declaración Ihlen señaló que "considera como indiscutible que tal respuesta a una gestión de un representante diplomático de una potencia extranjera, hecha por el ministro de Relaciones Exteriores a nombre de su gobierno, en un asunto que es de su resorte, vincula al país del que él es ministro" Ihlen de 22 de julio de 1919, Noruega se encuentra en la obligación de no disputar la soberanía danesa en toda Groenlandia y, con mayor razón, abstenerse de ocupar una parte de Groenlandia” .

En el fallo se puede observar que la CPJI califica la declaración Ihlen como un compromiso que constituye una respuesta a una gestión de un representante diplomático de Dinamarca. En este sentido, parte de la doctrina constata que la obligatoriedad del acto unilateral no se funda en la sola manifestación de voluntad de Noruega, sino que se funda en un acuerdo de voluntades no escrito, es decir, se trataría de un acto unilateral no autónomo o interdependiente de otro acto debido a las circunstancias de hecho en que se realizó, consistentes en que la declaración noruega se dio en una conversación en

\footnotetext{
3 Daillier, et al.,2009, p. 373.

${ }^{4}$ SiCAUlt, 1979, p. 637.

${ }^{5}$ CPJI, Dinamarca con Noruega, 5.10. I933, p. 71.

${ }^{6}$ Ibid., p. 73.
} 
que el ministro danés manifestó que su gobierno nada tenía que oponer a la extensión de la soberanía noruega a Spitzberg ${ }^{7}$. A partir de lo expuesto, la doctrina posterior a la sentencia funda el carácter obligatorio de los actos unilaterales en el consentimiento presunto del beneficiario, así como lo expresó Brierly ante la Comisión de Derecho Internacional $(\mathrm{CDI})^{8}$.

En 1957 es posible encontrar otro hito: la declaración de Egipto acerca del Canal de Suez. Dicho año, Egipto publicó la declaración del Canal de Suez, en la que después de su nacionalización daba seguridad respecto de su uso por los demás Estados. Sin embargo, al igual como ocurrió con la declaración Ihlen, para un sector de la doctrina dicho acto no es autónomo, ya que el gobierno egipcio en la declaración reafirmaba su sujeción a las obligaciones impuestas por el Convenio de Constantinopla de 1888, relativa a la libre navegación por el Canal de Suez ${ }^{9}$. Sin embargo, esto resulta impreciso, ya que la declaración a pesar de reafirmar obligaciones preexistentes también contiene nuevas obligaciones, como la obligación de garantizar que el Canal se mantenga y desarrolle de acuerdo con las exigencias de la navegación moderna y que una autoridad autónoma operaría el Canal ${ }^{10}$.

Las opiniones doctrinales respecto del fallo acerca del estatuto jurídico de Groenlandia Oriental y de la declaración de Egipto por el Canal de Suez, manifiestan la relevancia del carácter autónomo del acto para determinar su unilateralidad. Sin embargo, dicho concepto no es unívoco, lo que tiene consecuencias respecto del objeto de estudio.

En la década de los años sesenta del siglo XX la doctrina no estaba conteste en admitir la obligatoriedad de los actos unilaterales; es más, el tema no fue tratado de manera sistemática hasta esa época. Así por ejemplo, Kiss al momento de describir la práctica francesa de esos años concerniente al tema, afirma que " $[\mathrm{e}] \mathrm{l}$ principio fundamental que rige los actos unilaterales es que no comprometen ni al Estado del que ellos emanan, ni, con mayor razón, a los otros Estados" 11 . Una actitud contraria es la elegida por Suy, quien señala que "nosotros sostenemos la tesis que la promesa puramente unilateral existe en el derecho de gentes y que ella tiene un carácter obligatorio" ${ }^{2}$. Sin embargo, estima que, si bien "las promesas unilaterales existen en el derecho internacional, ellas son muy raras. Esta rareza se explica fácilmente puesto que ningún Estado se presta voluntariamente a hacer concesiones espontáneas y gratuitas. La detección de esas promesas puramente unilaterales exige un esfuerzo de investigación minuciosa para determinar si, detrás de la fachada de la unilateralidad formal de una declaración de voluntad, no se oculta una bilateralidad de fondo" ${ }^{13}$. A partir de ello, es posible afirmar que la resistencia de la doctrina internacionalista para reconocer el carácter obligatorio de la promesa unilateral

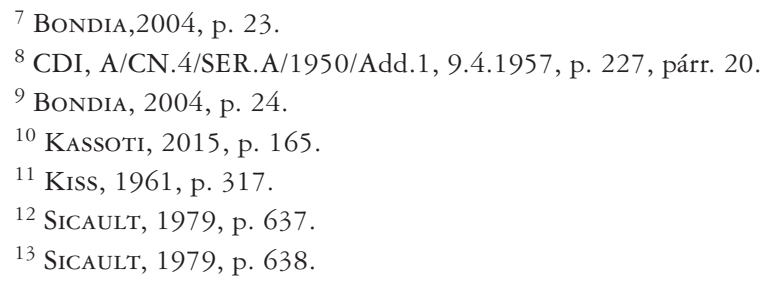


se debe fundamentalmente a la concepción contractual del derecho internacional, cuyo fundamento último es el principio pacta sunt servanda ${ }^{14}$.

Hasta la década de los setenta no existe consenso en la doctrina respecto de la obligatoriedad de los actos unilaterales. Sin embargo, esta situación se modifica en 1974 , a partir de los fallos de la CIJ por los denominados "asuntos de los ensayos nucleares". Precisamente, en 1973, Australia y Nueva Zelanda presentaron demandas en contra de Francia, solicitando a la CIJ que declarara que la continuación de las pruebas nucleares atmosféricas francesas en el Pacifico Sur eran incompatibles con el derecho internacional vigente y que ordenase a dicho Estado el cese de tales pruebas. A partir de ello, la CIJ analizó varias declaraciones realizadas por las autoridades francesas durante los meses de junio a octubre de 1974, específicamente del Presidente de la República, ministro de Defensa y ministro de Asuntos Exteriores, concluyendo que esas declaraciones unilaterales vinculan jurídicamente al Estado francés, el que tiene la obligación de no continuar con las pruebas nucleares.

En los fallos, la CIJ arriba a la conclusión señalada a partir de cuatro criterios, que son muy relevantes para la concepción contemporánea de este tipo de actos: un acto unilateral vinculará jurídicamente al Estado autor del mismo, cuando en dicho acto se exprese una específica voluntad de obligarse, afirmando de manera expresa el carácter estrictamente unilateral de los actos y de las obligaciones que se derivan de ellos ${ }^{15}$; los actos unilaterales pueden ser realizados en forma verbal o escrita ${ }^{16}$; la CIJ excluye tajantemente consideraciones de carácter contractual para explicar la obligación jurídica que nace del acto, afirmando incluso que dichas obligaciones tienen un carácter absoluto o erga omnes en relación con la comunidad internacional ${ }^{17}$; y que el fundamento de la obligatoriedad de los actos unilaterales, expresando que dicho carácter se basa en la buena $\mathrm{fe}^{18}$.

La buena fe a que se refiere la CIJ, es la buena fe objetiva ${ }^{19}$, entendiendo por tal un principio general del derecho que tiene por objeto la protección de las expectativas legítimas y de los objetivos enraizados en el interés colectivo ${ }^{20}$. Por tanto, es posible concluir que aun cuando se predique la autonomía del acto unilateral como una de sus características esenciales, se podría entender que su obligatoriedad depende de la confianza que el acto genera para su destinatario, es decir, de su reacción y expectativas frente al acto unilateral. Ello ha sido reafirmado por la CDI en el principio tercero del texto "Principios rectores aplicables a las declaraciones unilaterales de los Estados capaces de crear obligaciones jurídicas" (principios rectores) ${ }^{21}$, en que se contempla la reacción

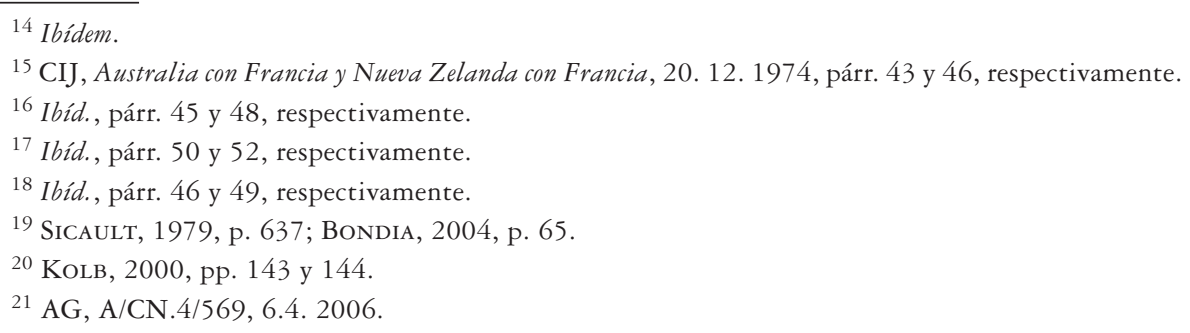


del destinatario del acto como una circunstancia para determinar los efectos jurídicos de una declaración unilateral.

En sentido contrario opina Kassoti, para quien la reacción del destinatario del acto no debe ser tomada en cuenta como una circunstancia que permita determinar el carácter vinculante de los actos unilaterales. En este sentido, ella señala que si bien dicha circunstancia se encuentra contemplada en el principio tercero del texto de los principios rectores, el fundamento que se tuvo en vista para su incorporación no tiene asidero en la realidad, debido a que en los fallos que se citan para justificarla, la CIJ no prestó particular atención a la reacción del destinatario para tomar su decisión. Ello se pone de manifiesto en el caso de los fallos de los "asuntos de los ensayos nucleares", donde Australia y Nueva Zelanda, destinatarios primitivos de las declaraciones de las autoridades francesas, "expresamente rechazaron la obligatoriedad de esas declaraciones" 22 .

Si bien lo expresado por Kassoti respecto de los fallos en comento puede considerarse acertado, ello no desvirtúa que mediante el principio de la buena objetiva se pueda concluir que una de las circunstancias para determinar el carácter vinculante de un acto unilateral sea la reacción del destinatario. Es más, cuando ella se refiere a la buena fe como base de la fuerza vinculante del acto unilateral señala que en su virtud el "derecho internacional atribuye efectos vinculantes a los actos unilaterales con el fin de proteger a otros Estados que pueden haber depositado razonablemente confianza en una manifestación expresa de voluntad" ${ }^{23}$. Dicho de otro modo, pone de manifiesto que la confianza del destinatario del acto es relevante para determinar la fuerza vinculante del acto unilateral.

Por último, es necesario mencionar los trabajos que ha realizado la CDI al respecto. En 1996 la CDI se abocó al estudio del tema, encontrando muchas dificultades en el desarrollo de su trabajo, especialmente por sus constantes cambios metodológicos y los problemas para hallar la práctica internacional respecto de la materia. Es por dichas razones que las discusiones en su seno se prolongaron por una década. Precisamente, el 2006, la Comisión redactó el texto de los principios rectores; el que no se trata de una convención con una regulación detallada, sino que buscan establecer criterios mínimos en relación con este tipo de actos ${ }^{24}$. El texto final de los principios rectores elabora un concepto de acto unilateral y reconoce su carácter obligatorio; establece principios de interpretación; reconoce requisitos de validez; y regula su revocación. No obstante ello, ha sido objeto de críticas, ya que asimila los actos unilaterales solo a declaraciones formales ${ }^{25}$.

A partir de lo analizado hasta ahora, podría concluirse que en la actualidad no habría discusión acerca de la idoneidad de los actos unilaterales de los Estados para producir efectos jurídicos. Sin embargo, ello no es así, ya que un sector de la doctrina

\footnotetext{
2221 Kassoti, 2015, p. 167.

23 Ibid., p. 173.

24 Torres, 2010, p. 167.

2525 Ibid., pp. 161-182.
} 
contemporánea todavía niega dicho carácter. Así por ejemplo, Thirlway estima que los actos unilaterales son tratados en formación, y es por ello que estos deben ser incorporados dentro del listado del artículo 38 del Estatuto de la CIJ "como una subdivisión de los 'tratados y convenciones', o un caso especial relacionado con ellos” ${ }^{26}$. El fundamento de ello se basa en la importancia que este autor otorga a la aceptación por parte de otro Estado, ya que si un acto unilateral no provoca ninguna reacción en el ámbito de las relaciones internacionales, este carece de relevancia o importancia jurídica ${ }^{27}$.

La crítica que se puede hacer al pensamiento de Thirlway, es que si el acto unilateral requiere de la aceptación de otro Estado para producir efectos jurídicos, la misma lógica se debería aplicar respecto de la costumbre internacional, ya que su elemento material está constituido por actos y comportamientos unilaterales, y por esta razón, el derecho consuetudinario no sería aplicable a los Estados que no han prestado su consentimiento pertinente al mismo. Precisamente, en este punto radica la inconsistencia de la tesis de Thirlway, porque al tratar el tema de la institución del objetor persistente, señala expresamente que una vez que una regla general de derecho consuetudinario se ha establecido "no hay posibilidad de convertirse tardíamente en un objetor persistente"28, lo que implica que la aceptación de la práctica unilateral no juega rol alguno en la producción de efectos jurídicos.

A partir de lo expuesto en este acápite, es posible constatar que la obligatoriedad de los actos unilaterales es sostenida por la jurisprudencia y gran parte de la doctrina internacionalista. Sin embargo, muchos de sus aspectos son objeto de discusión debido a que no existe una regulación general y obligatoria respecto del tema, por lo que no es posible afirmar aún la existencia de un régimen jurídico general aplicable a este tipo de actos.

\section{Delimitación conceptual}

Desde un punto de vista empírico, es posible apreciar que en el ámbito internacional existen distintos tipos de actos unilaterales realizados por los Estados, y que estos pueden adoptar diversas formas. A partir de ello, es necesario entregar un concepto de acto unilateral y analizar sus elementos más relevantes.

Para efectos de esta investigación se entiende por acto unilateral un comportamiento unilateral, independiente de un régimen convencional especial, realizado por un Estado y que es idóneo para producir efectos jurídicos en el ámbito internacional. Los elementos más discutidos del concepto son la autonomía del acto unilateral y su idoneidad para producir efectos jurídicos.

En relación con el tema de la autonomía de los actos unilaterales, es posible encontrar dos sentidos perfectamente distinguibles ${ }^{29}$. La primera estima que la autonomía del acto

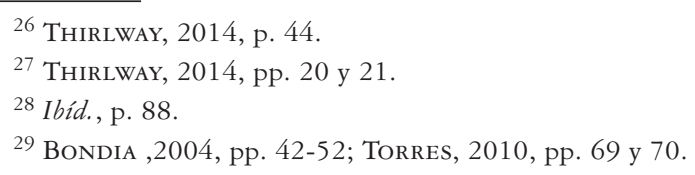


implica que para producir sus efectos jurídicos no requiere de la reacción o consentimiento de otros Estados, es decir, su carácter obligatorio se construye con independencia de la conducta de otro sujeto respecto del acto. Por dicha razón, existe discusión acerca del carácter de acto unilateral de la declaración Ihlen, ya que un sector de la doctrina estima que sería un acuerdo no escrito de carácter verbal, debido a que constituiría una respuesta a la declaración realizada por el ministro danés respecto de la voluntad de su gobierno de no oponerse a la extensión de la soberanía noruega a Spitzberg. Se puede estimar que la acepción en comento es lo que constituye la noción de acto unilateral en un sentido más estricto.

La segunda acepción del término se vincula con el hecho que el acto unilateral se realiza con independencia de una prescripción convencional o consuetudinaria. Por tanto, se dejaría fuera del concepto de acto unilateral, todos aquellos actos que tengan por objeto formar o aplicar el derecho convencional como, por ejemplo, es el caso de la ratificación de un tratado, la formulación de una reserva o la delimitación de un espacio marítimo o terrestre regulado en un tratado bilateral o multilateral; o aquellos actos que dan lugar o se aplican con ocasión de la ejecución de normas de carácter consuetudinario. Por tanto, en este sentido la autonomía se vincula con la existencia o no de un determinado marco jurídico regulatorio del acto.

Este tema se discutió también en la CDI. En un primer momento, el relator especial Rodríguez, concibió la autonomía en el sentido de la primera acepción explicada en este trabajo, entendiendo que el compromiso se contrae sin ninguna otra contrapartida o elemento de reciprocidad ${ }^{30}$. Sin embargo, esta postura no fue aceptada por los demás integrantes de la CDI. Por ejemplo, Pellet estima que la concepción de autonomía propuesta por el relator especial debe ser rechazada, porque tiene un carácter muy restringido, y por dicha razón, carece de ejemplos basados en la práctica internacional. Precisamente, el autor francés señala que "[p]ara atenerse estrictamente a esta idea de la autonomía de los actos en los que está interesado, el Relator Especial se priva de describir una práctica, ya que esta práctica existe sobre todo respecto de lo que el Relator Especial considera actos no autónomos"31.

Para los efectos de esta investigación, la primera acepción del concepto de autonomía no será tomada en cuenta, debido a que ella confunde la reciprocidad existente en el ámbito convencional con la reacción que pudiese producir el acto en los hechos, y que no tiene que ver con el valor jurídico del mismo; en otras palabras, confunde la autonomía jurídica con la autonomía fáctica del acto. Un ejemplo de lo expresado es la incomprensión que parte de la doctrina tiene acerca de la declaración Ihlen, en el sentido que esta se trataría de un acuerdo de carácter verbal, ya que se produjo con posterioridad a la declaración del ministro danés respecto de Spitzberg. Sin embargo, eso solo fue una cuestión de hecho que no afecta la autonomía de dicho acto en la producción de efectos jurídicos, ya que cumple con los requisitos de validez de un acto unilateral. Además,

\footnotetext{
${ }^{30}$ CDI, A/CN.4/SER.A/1998, p. 44, párr. 90.

${ }^{31}$ Ibíd., p. 209, párr. 13.
} 
esta concepción de autonomía no es conciliable con el método de interpretación de los actos unilaterales, contemplado en el principio tercero del texto de los principios rectores, en que se contempla que para determinar los efectos jurídicos de una declaración unilateral, se debe tomar en cuenta la reacción que suscitó.

La segunda acepción de autonomía será aplicada de manera restringida, en el sentido de excluir dentro de la noción de acto unilateral solo a aquellos actos sujetos a regímenes convencionales especiales, como es el caso de las reservas de los tratados, la forma de manifestar el consentimiento en obligarse por un tratado o las declaraciones de la aceptación de la jurisdicción obligatoria de un tribunal internacional. Para llegar a esta conclusión se sigue a Pellet, para quien no existe ninguna razón válida para eliminar, por ejemplo, los actos adoptados en aplicación de una regla consuetudinaria, como sería el caso de los actos unilaterales en virtud de los cuales los Estados definen la anchura de sus distintos espacios marítimos. Pertinente a este punto, el jurista francés se pregunta "si no puede considerarse que todos los actos unilaterales se fundan en una norma consuetudinaria, empezando por la que permite a los Estados a obligarse" ${ }^{\text {"32. }}$ Tomando en cuenta lo señalado, la noción de autonomía que se describe no excluye como acto unilateral a aquellos actos que forman o aplican el derecho consuetudinario.

Como consecuencia de lo anterior, la noción de acto unilateral adoptada en este trabajo incluye el silencio cualificado o aquiescencia, es decir, los denominados actos unilaterales presuntos o tácitos. En efecto, si bien no parecen existir dudas que el silencio o aquiescencia en determinadas circunstancias puede producir consecuencias jurídicas, como es el caso que frente a una determinada situación es necesario realizar una protesta y ella no se lleva a cabo ${ }^{33}$, no existe consenso acerca de su inclusión dentro del concepto de acto unilateral. La principal justificación para su exclusión se basa en que el silencio o aquiescencia no constituye una manifestación de voluntad de carácter autónoma.

Lo señalado se pone de manifiesto en el fallo de la "delimitación de la frontera marítima en la región del golfo de Maine”, en que la CIJ expresa que la aquiescencia es "un reconocimiento tácito manifestado mediante un comportamiento unilateral que la otra parte puede interpretar como un consentimiento" 34 . Dicha situación ya fue advertida por Sicault en la década de los sesenta del siglo pasado, cuando sostuvo que "el silencio, como no puede producir efectos jurídicos de manera autónoma y tiene necesidad para ello de otro acto, no entra en la definición de compromiso unilateral" ${ }^{35}$. En este mismo sentido se pronuncian Jiménez ${ }^{36}$ y Torres $^{37}$.

En relación con el tema es necesario realizar dos comentarios. El primero se vincula con la naturaleza del silencio cualificado o aquiescencia. Para los efectos de este trabajo el silencio no constituye una manifestación de voluntad, a diferencia de lo que postula

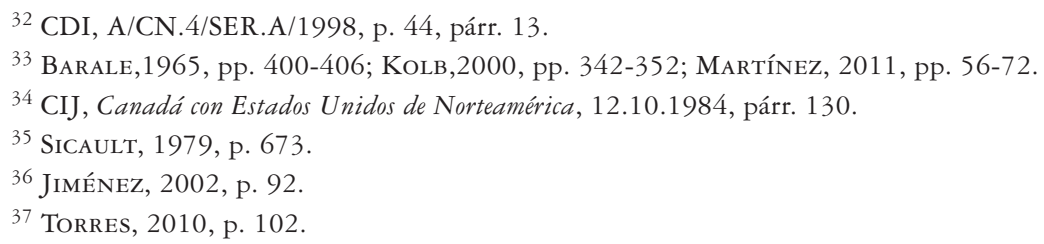


la escuela voluntarista, debido a lo expuesto arriba, en el sentido que solo es una ficción que produce efectos jurídicos en circunstancias excepcionales, para proteger las expectativas legítimas de un tercero. Ello pone de manifiesto que en el derecho internacional la voluntad no es la única vía para producir efectos jurídicos o crear derecho ${ }^{38}$.

El segundo, dice relación con la calificación del silencio cualificado o aquiescencia como acto unilateral. Como se puede apreciar de las citas realizadas, la doctrina que rechaza la aquiescencia como acto unilateral se basa en que esta no tendría un carácter autónomo, en el sentido de depender su fuerza jurídica del elemento de la reciprocidad. Sin embargo, y como se dejó en claro cuando se analizó la autonomía como característica del acto unilateral, el hecho que se tome en cuenta la reacción o expectativas del destinatario no convierte el acto en convencional. Es más, si no se toman en cuenta dichos elementos se estaría negando el fundamento del carácter obligatorio de los actos unilaterales, la buena fe objetiva.

En resumen, la aquiescencia o silencio cualificado es un comportamiento unilateral que produce efectos jurídicos en determinadas circunstancias, por lo que nada obstaría a que fuese calificado como acto unilateral ${ }^{39}$. Dicho de otra manera, en esta investigación se estima que el concepto de acto unilateral es más amplio que una declaración de voluntad, ya que su concepto estriba en la producción de efectos jurídicos producto de un comportamiento imputable a un solo Estado.

El segundo elemento del concepto dice relación con la distinción entre actos unilaterales de carácter jurídico y aquellos que tienen un carácter político. En efecto, este trabajo abordará el estudio de los actos unilaterales que tienen por objeto producir efectos jurídicos. Sin embargo, el problema de esta distinción radica en el hecho que no existen criterios generales para determinar de manera precisa cuando se está en presencia de unos y otros, sobre todo si se tiene en cuenta que los actos unilaterales de los Estados en el ámbito internacional siempre tienen un valor político.

La distinción entre actos unilaterales de carácter jurídico y de carácter político puede encontrarse en el voto disidente del juez Castro en los fallos de los "asuntos de los ensayos nucleares" ${ }^{40}$, en donde se limita a expresar la existencia de una distinción entre actos que producen obligaciones jurídicas y aquellos que producen una obligación que denomina "moral", sin indicar criterios que permitan efectuar esa diferenciación.

Kassoti propone algunos criterios para determinar el carácter jurídico de un acto unilateral, que para ella se manifiesta en la determinación de la intención de obligarse ${ }^{41}$. Para estos efectos propone los siguientes criterios: el contenido del acto; la publicidad del acto; el lugar o circunstancia en que se realizó el acto; el autor del acto; y el hecho que el acto haya sido registrado de conformidad con el artículo 102 de la Carta de las Naciones Unidas ${ }^{42}$. Además, y de acuerdo con lo señalado arriba, también debería

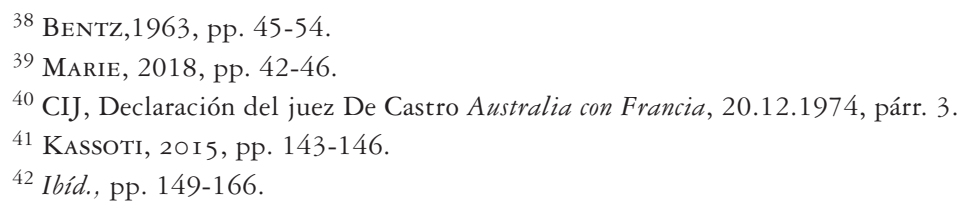


agregarse la reacción del destinatario del acto como una de las circunstancias a tener en cuenta, y que Kassoti niega por los motivos expuestos anteriormente.

Este elemento fue determinante para que la CIJ en el asunto de "la obligación de negociar un acceso al océano Pacífico”, rechazara el carácter jurídico de las declaraciones y actos unilaterales formulados por Chile, y que fueron esgrimidos por Bolivia para demandar a este último. Precisamente, Bolivia mencionó ciertas declaraciones y actos unilaterales de Chile que, consideradas individualmente o en su conjunto, establecerían una obligación jurídica de negociar ${ }^{43}$. En la sentencia del caso en comento, la CIJ señaló que " $[\mathrm{e}] \mathrm{n}$ cuanto a las circunstancias que rodearon las diferentes declaraciones del demandado, la Corte observa que no existe ninguna prueba de una intención, de parte de este, de asumir una obligación de negociar" ${ }^{4}$. Para comprender lo señalado por el tribunal, es necesario tener en cuenta que la pretensión boliviana se fundaba en declaraciones y comportamientos que, al menos en el estado actual de la doctrina, no tienen la idoneidad de producir efectos jurídicos. Precisamente, un acto unilateral no puede generar obligaciones si tiene por objeto la proposición de realizar un proceso político de negociación que tiene por finalidad la celebración de un acuerdo internacional, ya que ello implica afirmar que una oferta de carácter político destinada a negociar una obligación jurídica de tipo convencional, sea a su vez una fuente de derecho. Ello podría explicar lo expresado por la CIJ al señalar "que las declaraciones y otros actos unilaterales de Chile invocados por el solicitante no denotan que una obligación jurídica haya sido suscrita por el demandado, sino que este último estaba dispuesto a iniciar negociaciones sobre la cuestión del acceso soberano de Bolivia al océano Pacífico" ${ }^{4}$.

\section{REQUisitos DE VALIDEZ Y EFECTOS DE LOS ACTOS UNILATERALES}

\section{Requisitos de validez}

A partir de lo señalado en los principios primero, cuarto, quinto, sexto, séptimo y octavo de los principios rectores de la CDI, y las consideraciones realizadas en el acápite anterior, es posible colegir tres requisitos, a saber: el acto unilateral debe ser realizado por un órgano del Estado competente para obligarlo internacionalmente; la existencia de un comportamiento respecto del que se pueda interpretar una intención de producir efectos jurídicos; y que el acto unilateral no puede ser contrario a una norma imperativa

${ }^{43}$ Las declaraciones y actos unilaterales realizadas por Chile, y que fundan la demanda boliviana son, el memorándum de 9 de septiembre de 2019; la declaración de 28 de septiembre de 1921 ante la Sociedad de las Naciones; la nota diplomática de 6 de febrero de 1923; la declaración presidencial de 29 de marzo de 1951; la declaración presidencial de 11 de septiembre de 1975; la nota diplomática de 19 de diciembre de 1975; la declaración de 31 de octubre de 1979 ante la Asamblea General de la Organización de Estados Americanos; el discurso de 21 de abril de 1987. CIJ, Bolivia con Chile, 1.10.2018, párr. 142 y 143.

${ }^{4}$ Ibid., párr. 148.

45 CIJ, Bolivia con Chile, 1.10.2018, párr. 147. 
de derecho internacional general o dictado con la finalidad de eludir el cumplimiento de una obligación internacional. A continuación se examinarán los requisitos señalados.

a) El acto unilateral debe ser realizado por un órgano del Estado competente para obligarlo internacionalmente

A diferencia de lo que ocurre en el derecho de los tratados, en el ámbito de los actos unilaterales no existe una regulación general y obligatoria al respecto. Por tanto, el cumplimiento de este requisito dependerá de los criterios que al efecto establezca la jurisprudencia, y las recomendaciones contenidas en los principios rectores.

Una primera aproximación al tema permite constatar que es un criterio establecido en la jurisprudencia internacional estimar que por el mero hecho de ejercer sus funciones, los jefes de Estado, los jefes de gobierno y los ministros de Relaciones Exteriores representan a los Estados a que pertenecen ${ }^{46}$. También es posible apreciar como una práctica jurisprudencial instaurado, que se reconoce que personas que representan a un Estado en determinados ámbitos sean autorizadas por este para obligarlo mediante sus declaraciones en las materias de su competencia, como es el caso de los titulares de carteras ministeriales técnicas u otros funcionarios ${ }^{47}$.

De los criterios citados se puede concluir la necesidad que los Estados logren una unidad de acción en sus asuntos exteriores, en el ámbito de su actuación unilateral. De lo contrario, es posible que el Estado pueda ser comprometido internacionalmente por un acto o declaración unilateral realizado por un funcionario distinto al jefe de Estado, jefe de gobierno o ministro de Relaciones Exteriores. En efecto, a partir de la práctica jurisprudencial en comento, surge la interrogante de determinar qué funcionarios son los que pueden comprometer unilateralmente al Estado. La respuesta a la pregunta no es trivial, ya que las relaciones internacionales en la actualidad son muy complejas, y abarcan múltiples esferas de competencia que incluso pueden exceder a las que usualmente se entienden atribuidas al poder ejecutivo, estructura de la organización estatal a la que normalmente se atribuyen competencias relativas a la conducción de las relaciones internacionales o para realizar actuaciones con efectos en el ámbito internacional.

En el sentido expuesto, se pueden dar como ejemplos las actuaciones o declaraciones de parlamentarios o incluso sentencias de tribunales superiores de justicia de un Estado determinado, que tengan un efecto en el ámbito internacional. Acerca de esta última hipótesis, y en el caso específico de Chile, si se adopta una concepción amplia de este requisito, se podría llegar a sostener que los criterios establecidos por la Corte Suprema (CS) en la sentencia de protección de 18 de noviembre de 2015, pronunciada en contra de Venezuela, podrían haber obligado en próximas ocasiones al Estado de Chile en reconocer la jurisdicción de un tribunal extranjero respecto de hechos ocurridos en Chile

${ }^{46}$ CIJ, Decisión sobre excepción preliminar República Democrática del Congo con Ruanda, 3.2.2006, párr. 46.

47 CIJ, Francia con Reino Unido, 17.11.1953, p. 28; CIJ, Nicaragua con Estados Unidos de Norteamérica, 27.6.1986, párr. 64; CIJ, Decisión sobre excepción preliminar República Democrática del Congo con Ruanda, 3.2.2006, párr. 47. 
por materias que exceden el ámbito de aplicación acotado de la jurisdicción universal, y respecto de los que carece de competencia ${ }^{48}$. Precisamente, en dicha sentencia la Corte Suprema conociendo en segunda instancia de una acción de protección interpuesta en contra de la República Bolivariana de Venezuela a favor de dos venezolanos, acoge la acción, fallando una controversia relativa a extranjeros por hechos ocurridos fuera de Chile, tomando como base una discutida jurisdicción protectora de los derechos humanos, instruyendo al Ministerio de Relaciones Exteriores que le solicite a la Comisión Interamericana que visite Venezuela y que efectúe un informe ${ }^{49}$. Sin perjuicio de las críticas que se pueden realizar al fallo por la construcción de las nociones de ius cogens y de jurisdicción universal ${ }^{50}$, surge la interrogante si dicha actuación unilateral podría obligar a Chile en próximas ocasiones, tomando en cuenta lo señalado arriba.

A juicio de quien suscribe estas líneas, la respuesta a la interrogante debe ser restrictiva, en el sentido que se debe tomar en cuenta la competencia acerca de asuntos internacionales asignada por el derecho interno. En efecto, si se toma en cuenta que la jurisprudencia ha ampliado la capacidad de obligar internacionalmente a un Estado a funcionarios estatales distintos del jefe de Estado, jefe de gobierno o ministro de Relaciones Exteriores, la única manera que exista una unidad de acción del Estado en asuntos internacionales es a partir de la presencia de una relación de carácter vicarial en este ámbito. Por tanto, si se le otorga capacidad de comprometer internacionalmente al Estado, a órganos que se encuentran fuera de dicha relación vicarial, la unidad de acción estatal en el ámbito internacional sería imposible de alcanzar. Sin embargo, es necesario expresar que, si la actuación de dichos órganos es convalidada por los órganos competentes para ello, según lo establecido en el derecho interno, se debería comprometer unilateralmente al Estado. Por ejemplo, ello habría ocurrido en el caso de la sentencia de la Corte Suprema mencionada arriba, si el Ministerio de Relaciones Exteriores hubiese dado cumplimiento a lo ordenado por dicha resolución ${ }^{51}$.

b) La existencia de un comportamiento respecto del que se pueda interpretar una intención de producir efectos jurídicos

El acto unilateral puede consistir tanto en una manifestación de voluntad como en un reconocimiento tácito manifestado en un comportamiento unilateral. Es por ello que a continuación se realizará un análisis de las exigencias necesarias para que cada una de

${ }^{48}$ Las materias que se encuentran dentro del ámbito de aplicación de la jurisdicción universal son la piratería, la esclavitud, los crímenes de guerra, los crímenes contra la humanidad, el genocidio, el apartheid y la tortura. López, 2016, p. 580.

${ }^{49} \mathrm{CS}, 18.12 .2015$, rol No 17.393 , cons. $10^{\circ}$.

${ }^{50}$ López, 2016, pp. 575-590.

${ }^{51}$ Se debe recordar que en el caso en comento, el Consejo de Defensa del Estado interpuso una acción de nulidad procesal de todo lo obrado en la causa, y en su virtud, la Corte Suprema modificó la sentencia de protección ordenando que sea ella misma y no el Ministerio de Relaciones Exteriores quien efectúe el requerimiento ante la Comisión Interamericana de Derechos Humanos. 
ellas pueda generar una obligación jurídica, para luego revisar la forma de interpretar dichos comportamientos.

Respecto de los actos unilaterales que consisten en una manifestación de voluntad, la jurisprudencia de la CIJ ha establecido que ella puede ser realizada de manera oral o escrita ${ }^{52}$. Ello también se encuentra recogido en el principio quinto del texto de los principios rectores de la CDI. Además, se exige que la declaración sea realizada de manera pública, ya sea que se dirija a la comunidad internacional en su conjunto o a uno o varios Estados o a otras entidades, utilizando como medio de publicidad la notificación o la declaración pública, según sea el caso ${ }^{53}$.

Por su parte, en lo que respecta a la aquiescencia, las condiciones con las que produce efectos jurídicos son las siguientes: el transcurso de un determinado tiempo, el conocimiento de los hechos o la situación por parte del sujeto al que se le imputa el silencio, y lo que se denomina la cualificación del silencio o la constatación de que el sujeto que guardó silencio pudo y debió actuar ${ }^{54}$. A continuación se analizarán cada uno de estos requisitos.

Respecto del transcurso del tiempo no existe un plazo determinado a partir de cuándo la aquiescencia producirá efectos jurídicos, sino que dependerá de las circunstancias del caso. Lo que sí se tiene claro, es que este requisito no se puede cumplir de manera instantánea, ya que se requieren diversos comportamientos que conforman un comportamiento global ${ }^{55}$. Por tanto, existe una relatividad acerca del factor temporal, lo que se ve reflejado en la jurisprudencia internacional. Así por ejemplo, en la sentencia de las "Pesquerías anglo noruegas", la CIJ estableció que la aquiescencia del Reino Unido se constituyó por su falta de reacción durante más de sesenta años ${ }^{56}$, y en el caso del fallo en el asunto del "Laudo arbitral del Rey de España", el mismo tribunal estimó que la pérdida del derecho de Nicaragua, para impugnar la validez de la sentencia arbitral por una designación irregular del árbitro, se verificó después de una tolerancia de seis años ${ }^{57}$.

En cuanto al segundo requisito, la doctrina es conteste en determinar que es una condición esencial para la producción de efectos jurídicos del silencio o aquiescencia, ya que no sería posible considerar que el comportamiento tácito de un sujeto produzca aquiescencia en una situación que ignora, o dicho de otra manera, si se estima que la aquiescencia constituye una ausencia de protesta debiendo hacerla, esta no podría realizarse si el sujeto no conoce la situación que la amerita ${ }^{58}$. Por tanto, para que el silencio sea imputable al sujeto es necesario que este haya debido conocer los hechos según el estándar de diligencia razonable, es decir, su desconocimiento debe aparecer como

\footnotetext{
52 CIJ, Australia con Francia y Nueva Zelanda con Francia, 20. 12.1974, párr. 49 y 51, respectivamente.

53 Sicault, 1979, p. 670; Barsalou, 2006, pp. 414.

54 Barale, 1965, pp. 400-406; Kolb, 2000, pp. 342-352; Martínez, 2011, pp. 56-72.

55 Barale, 1965, p. 393; Kolb, 2000, p. 343.

56 CIJ, Reino Unido con Noruega, 18.12.1951, p. 26.

57 CIJ, Honduras con Nicaragua, 18.11.1960, p. 15.

58 Barale, 1965, p. 401.
} 
culpable ${ }^{59}$. Así lo estimó la CIJ en el caso de las "Pesquerías anglo noruegas", donde estableció que el Reino Unido no pudo ignorar el sistema de líneas de bases establecidos por el reino de Noruega, tomando en cuenta su carácter de potencia marítima tradicionalmente cuidadosa del derecho del mar y la defensa de la libertad de los mares ${ }^{60}$. Otro ejemplo es la sentencia de la CIJ respecto del asunto del “Templo de Preah Vihear", en que no se consideró como una circunstancia que excluye la aquiescencia, la ignorancia de Tailandia respecto de las inexactitudes del mapa que delimita la frontera con Camboya, ya que el mapa fue conocido por funcionarios tailandeses subalternos, por lo que, tomando en cuenta sus cualidades y competencias es difícil que hubiese podido invocar la existencia de un error, ya que contribuyó a su producción ${ }^{61}$.

Respecto del tercer requisito, es necesario dejar en claro que no todo silencio que cumple con las dos condiciones señaladas arriba constituye aquiescencia, sino que solo aquel que tiene el carácter de cualificado, es decir, debe constatarse la existencia de un deber jurídico de oponerse a una pretensión de otro sujeto, mediante la realización de una protesta ${ }^{62}$. La CIJ se refirió a este requisito en la sentencia acerca del asunto de "la obligación de negociar un acceso al océano Pacífico", ya que Bolivia sostuvo que el silencio de Chile a la declaración boliviana de 27 de noviembre de 1984, realizada luego de haber firmado la Convención sobre el derecho del mar, en que expresó la existencia de negociaciones en vistas a restablecer su acceso al Pacífico, constituía aquiescencia ${ }^{63}$. El tribunal rechazó la pretensión boliviana fundada en la aquiescencia de Chile, ya que "Bolivia no mencionó ninguna declaración que hubiera exigido una respuesta o reacción de Chile para impedir que una obligación surja" ${ }^{64}$, lo que viene a reafirmar lo señalado en esta investigación, en el sentido que no existe una obligación general de protestar ${ }^{65}$.

Como último tema a tratar en este acápite, se encuentra lo relacionado con la interpretación de los comportamientos analizados, en el sentido de establecer qué forma de interpretación se utilizará para determinar que estos producirán efectos jurídicos. A modo de prevención, es necesario señalar que independiente del sistema de interpretación que se utilice, los actos unilaterales deben ser interpretados de manera restrictiva. Así

\footnotetext{
${ }^{59}$ KolB, 2000, p. 346.

${ }^{60}$ CIJ, Reino Unido con Noruega, 18.12.1951 p. 27.

${ }^{61}$ CIJ, Camboya con Tailandia, 15.6. 1962, p. 25.

${ }^{62}$ Kolb, 2000, pp. 347-352.

${ }^{63}$ CIJ, Bolivia con Chile, 1.10.2018, párr. 150.

${ }^{64}$ Ibid., párr. 152.
}

${ }^{65}$ Sin perjuicio de ello, hay autores que sostienen que el principio general de la buena objetiva puede servir como parámetro que permita colegir determinados factores en virtud de los cuales una parte podría tener confianza en que la otra tiene el deber de actuar, como por ejemplo: los comportamientos pasados; la naturaleza de la relación y su necesidad de estabilidad o de seguridad jurídica; el grado de vinculación entre las partes; la importancia de los intereses en juego; y, la hipótesis en que un comportamiento o pretensión afecte directamente los intereses, los derechos y la esfera protegida de un sujeto de derecho internacional. Kolb, 2000, p. 349. 
lo señala el principio séptimo del texto de los principios rectores y la jurisprudencia de la $\mathrm{CIJ}^{66}$.

Existen muchos métodos, sistemas o criterios de interpretación de los actos unilaterales, a saber: el sistema de la voluntad declarada; el método de la interpretación teleológica; el método que toma en cuenta la reacción de los destinatarios del acto; y el método que toma en cuenta las circunstancias que rodean el acto o comportamiento ${ }^{67}$. En la práctica internacional se utilizan de manera conjunta los métodos o criterios de la reacción y de las circunstancias para determinar los efectos jurídicos del acto ${ }^{68}$. Ello se manifiesta en los principios tercero y séptimo del texto de los principios rectores de la CDI y en la jurisprudencia de la $\mathrm{CIJ}^{69}$.

c) El acto unilateral no puede ser contrario a una norma imperativa de derecho internacional general o dictado con la finalidad de eludir el cumplimiento de una obligación internacional.

El requisito consta de dos partes perfectamente distinguibles y que responden a dos situaciones distintas. Precisamente, que el acto unilateral no pueda ser contrario a una norma imperativa de derecho internacional general, se refiere a la licitud del objeto del acto; en cambio, que el acto no pueda ser dictado con la finalidad de eludir el cumplimiento de una obligación internacional, alude a la licitud de la finalidad del acto unilateral. Así como señala Sicault, " [l]a licitud del objeto del compromiso internacional no es suficiente; ella debe ser igualmente acompañada por la licitud de la finalidad. Las dos nociones deben ser, en efecto, bien distinguidas, el objeto se confunde con la norma creada mientras que la finalidad se puede definir como el resultado buscado en la emisión del acto"70. A continuación se analizarán ambos casos.

En cuanto a la licitud del objeto, esta se traduce en la "imposibilidad de contradecir una norma de ius cogens" 71 , lo que implica que esta no puede ser derogada por un acto unilateral de un Estado. Las normas imperativas de derecho internacional general o normas de ius cogens constituyen una manifestación de la estructura comunitaria de la sociedad internacional y del derecho internacional público, que tienen por objeto limitar la voluntad de los Estados para proteger intereses colectivos de la comunidad internacional ${ }^{72}$.

${ }^{66}$ CIJ, Australia con Francia y Nueva Zelanda con Francia, 20. 12.1974, párr. 44 y 47, respectivamente; CIJ, Burkina Faso con República de Mali, 22.12.1986, párr. 39.

${ }^{67}$ Barsalou, 2006, pp. 407-414.

68 Incluso no es erróneo estimar que la reacción del o los destinatarios del acto constituyan una circunstancia más del acto unilateral.

${ }^{69}$ CIJ, Australia con Francia y Nueva Zelanda con Francia, 20. 12.1974 párr. 49 y 51, respectivamente; CIJ, Burkina Faso con República de Mali, 22.12.1986, párr. 40; CIJ, Decisión sobre excepción preliminar República Democrática del Congo con Ruanda, 3.2.2006, párr. 49.

${ }^{70}$ Sicault, 1979 , p. 664.

${ }^{71}$ BONDia, 2004, p. 120.

72 Diez de Velasco, 2015, p. 83; Díaz, 2014, pp. 555 y 556. 
La primera manifestación positiva del ius cogens, y que tiene incidencia para el objeto de este trabajo, es la de los artículos 53 y 64 de la Convención de Viena acerca del derecho de los tratados, en que se establece la nulidad y terminación de los tratados contrarios a este tipo de normas. Precisamente, a partir de este reconocimiento positivo en el ámbito de los tratados internacionales, la doctrina internacionalista comenzó a predicar la aplicación de una regla similar en el ámbito de los actos unilaterales, lo que tiene lógica tomando en cuenta que los actos unilaterales pueden producir efectos que contravienen los intereses colectivos esenciales de la comunidad internacional.

En cuanto a la licitud de la finalidad del acto, autores como Sicault y Bondia entienden que este requisito se cumple si el acto no busca eludir una obligación internacional73. Si bien ello no se encuentra recogido en los principios rectores, se hace necesario explicitarlo, ya que no es posible entenderlo incorporado, en el estado actual de la cuestión, como una infracción a una norma imperativa de derecho internacional general, sobre todo si se toma en cuenta que el principio acta sunt servanda no ha sido calificado como norma de ius cogens. Efectivamente, sin esta consideración sería posible sostener que un acto unilateral que tiene por finalidad eludir una obligación internacional emanada de otro acto unilateral, es válido.

\section{Efectos de los actos unilaterales}

Con el objeto de estudiar este tema, se realizará un análisis de los efectos jurídicos de los actos unilaterales respecto del Estado autor y respecto de terceros Estados.

La regla general del tema en comento, es que los actos unilaterales son jurídicamente vinculantes para su autor, siempre que dicho acto cumpla con los requisitos de validez analizados anteriormente en este trabajo. Precisamente, la oponibilidad de los actos unilaterales a su autor se explica a partir de la figura del estoppel. El estoppel no es una creación propia del derecho internacional público, sino que es una institución que nace en el derecho privado anglosajón, y que es semejante a la idea presente en el sistema europeo continental de la doctrina de los actos propios. Precisamente, uno de los trabajos más completos respecto del origen, naturaleza, requisitos y tipos de estoppel, se encuentra presente en la investigación realizada por Díez-Picazo acerca de dicha doctrina $^{74}$. En este trabajo, su autor señala que la eficacia del estoppel es puramente procesal, ya que "significa que dentro de un proceso una persona no puede hacer una alegación en contradicción con el sentido objetivo de su anterior conducta" 75 . Por tanto, es posible apreciar que el estoppel "imposibilita una determinada alegación y hace que se le considere inadmisible" 76 .

\footnotetext{
73 Sicault, 1979, p. 664; Bondia, 2004, p. 122.

${ }^{74}$ Díez-Picazo (1963), pp. 61-85.

75 Ibid., p. 67.

76 Ibid., p. 68.
} 
La recepción del estoppel en el derecho internacional público se puede explicar a partir del rol que juega la voluntad y comportamiento de los Estados en esta rama del derecho, donde la libertad y posibilidades de actuación de los Estados es muy amplia ${ }^{77}$. Lo señalado precedentemente se manifiesta en los elementos esenciales del estoppel. De acuerdo con lo expresado por la doctrina ${ }^{78}$ y la jurisprudencia ${ }^{79}$, los requisitos para que se configure el estoppel son tres. En primer lugar, una situación creada por una actitud de una parte; en segundo lugar, una conducta seguida por la otra parte, y basada directamente en la primera actitud, ya sea en su perjuicio o en beneficio de la parte que realizó la conducta primaria; y en tercer lugar, una imposibilidad por parte del que adoptó la primera actitud de alegar contra ella o manifestarse en sentido contrario. Por tanto, la conducta del Estado manifestada en el acto unilateral lo vincula a seguir comportándose de la misma manera, especialmente si ello crea en terceros de buena fe una expectativa que la conducta seguirá realizándose de acuerdo con los mismos parámetros.

A partir de los requisitos indicados en el párrafo precedente, la CIJ rechazó la pretensión boliviana que se basaba en la figura del estoppel para fundar la supuesta obligación de Chile para negociar un acceso soberano al mar. Precisamente, el tribunal indicó que, en relación con las actuaciones de Chile, "Bolivia no acreditó que ella haya modificado su posición en su perjuicio o en beneficio de Chile fundándose en las posiciones tomadas por este" 80 .

Como consecuencia de lo expresado, el Estado autor de un acto unilateral no lo puede revocar arbitrariamente. Ello fue recogido en el principio décimo del texto de los principios rectores, que señala que una de las cuestiones a tener en cuenta para determinar si una revocación es o no arbitraria, es la medida en que los sujetos a quienes se deba el cumplimiento de las obligaciones se hayan basado en ellas, esto es, que no se haya generado alguna expectativa en el destinatario del acto o que este haya actuado a base de la misma. En este mismo sentido, la CIJ en la sentencia por competencia y admisibilidad en el "asunto de las actividades militares y paramilitares en y contra Nicaragua" 81 .

Referente a los efectos de los actos unilaterales respecto de terceros, la doctrina estima que los actos unilaterales solo atribuyen derechos a terceros y no obligaciones ${ }^{82}$. Sin embargo, de ello no se debe deducir que un acto unilateral no originarían algunas situaciones que serían oponibles a terceros Estados, ya que estos pueden consentir en vincularse a los efectos jurídicos emanados del acto unilateral. Por tanto, se desprende que la oponibilidad del acto unilateral frente a terceros no se origina del acto mismo, sino que de un acto posterior.

\footnotetext{
77 PeCOURT (1962), p. 102.

${ }^{78}$ Ibid., p. 103.

${ }^{79}$ CIJ, Bolivia con Chile, 1.10.2018, párr. 153.

${ }^{80}$ CIJ, Bolivia con Chile, 1.10.2018, párr. 159.

${ }^{81}$ CIJ, Decisión sobre excepción preliminar Nicaragua con Estados Unidos de Norteamérica, 26.11.1984,

82 Miaja de la Muela, 1967, p. 447; Diez de Velasco, 2015, p. 153.
} párr. 51. 
Los actos unilaterales tienen un efecto general cuando originan una práctica consuetudinaria en terceros Estados ${ }^{83}$. Un ejemplo de ello es lo ocurrido con la denominada Proclamación Truman de 1945, en que Estados Unidos de Norteamérica se propuso limitar los derechos de terceros Estados en su plataforma continental. En poco tiempo, la regla contenida en la Proclamación fue aceptada generalmente por otros Estados, e incluso fue considerada por la CDI al elaborar los proyectos de convenciones del derecho del mar.

En definitiva, el acto unilateral como origen o fuente de una norma internacional general se materializa mediante una práctica que constituye costumbre y que se impone frente terceros Estados. Dicha imposición se puede manifestar por medio de un acto expreso, de un acto presunto o del consentimiento tácito.

\section{Conclusiones}

El trabajo estableció las hipótesis bajo las cuales un acto unilateral de carácter estatal puede producir efectos jurídicos en el ámbito internacional. Ello se realizó fundamentalmente a partir de una delimitación conceptual y el establecimiento de los requisitos que un acto unilateral debe cumplir para que sea idóneo para producir efectos jurídicos en el ámbito internacional. Acerca de ello hay que realizar dos precisiones. En primer lugar, se constató que la noción de acto unilateral no se identifica solamente con una declaración de voluntad expresa, sino que también puede consistir en un reconocimiento tácito manifestado en un comportamiento unilateral, como es el caso de la aquiescencia. Ello implica que para la configuración de un acto unilateral debe existir un comportamiento respecto del que se pueda interpretar una intención de obligarse, independiente de que exista una manifestación de voluntad de su autor en dicho sentido.

En segundo lugar, se estableció que la diferencia entre un acto jurídico unilateral y un acto unilateral de carácter político se basa fundamentalmente en las circunstancias de su realización. En efecto, la determinación de los efectos jurídicos de un acto unilateral se debe realizar a partir del examen de aspectos circunstanciales, tales como, su contenido, publicidad, el lugar en que fue realizado, el autor del acto y la reacción de su destinatario.

Por último, es menester señalar que los criterios establecidos en el trabajo sirven de parámetro para evaluar la producción de efectos jurídicos en el ámbito internacional de los comportamientos de los órganos nacionales que no tienen a su cargo las relaciones internacionales del Estado de Chile, como por ejemplo, actuaciones de las Cámaras del Congreso Nacional, del Poder Judicial o demás órganos autónomos existentes. Precisamente, así como lo puso de manifiesto el análisis realizado en este trabajo a la sentencia de protección de la Corte Suprema de 18 de noviembre de 2015, pronunciada en contra de Venezuela, no existe conciencia, por parte de aquellos órganos estatales que no tienen a su cargo las relaciones internacionales, que sus actuaciones también pueden ser

${ }^{83}$ Diez de Velasco, 2015, pp. 153 y 154. 
idóneos para producir efectos jurídicos en el ámbito internacional, y que por esta razón, en determinadas circunstancias, podrían servir de base para la construcción de una regla de derecho internacional y generar obligaciones jurídicas para la República de Chile.

\section{BIBLIOGRAFÍA}

\section{Doctrina}

BARAle, J., 1965: "L'acquiescement dans la jurisprudence international", Annuaire Française de Droit International, vol. 11, $\mathrm{N}^{\circ} 1$.

Barsalou, O., 2006: "Les actes unilatéraux étatiques en droit international public: observations sur quelques incertitudes théoriques et pratiques", The Canadian Yearbook of International Law, vol. 54.

Benadava, S., 2004: Derecho Internacional Público (8a edición), Santiago, Lexis Nexis.

Bentz, J., 1963: "Le silence comme manifestation de volonté en droit international public", Revue Générale de Droit International Public, No 1.

Bondia, D., 2004: Régimen Jurídico de los Actos Unilaterales de los Estados, Barcelona, J.M. Bosch Editor.

Daillier, P.; Forteau, M.; Pellet, A., 2009: Droit international public ( $8^{a}$ edición), París, Lextenso éditions.

DíAz, R., 2014: "El reconocimiento del ius cogens en el ordenamiento jurídico chileno", Revista Chilena de Derecho, vol. 41, No 2 .

Diez de Velasco, M., 2015: Instituciones de Derecho Internacional Público (18 a edición), Madrid, Tecnos.

Díez-Picazo, L., 1963: La doctrina de los propios actos, Barcelona, Bosch.

JimÉnez, F., 2002: Los comportamientos recíprocos en derecho internacional. A propósito de la aquiescencia, el estoppel y la confianza legítima, Madrid, Editorial Dilex.

Kassoti, E., 2015: The Juridical Nature of Unilateral Acts of States in International Law, Leiden, Brill-Nijhoff.

KIss, A., 1961: "Les actes unilatéraux dans la pratique française du droit international", Revue Générale de Droit International Public, $\mathrm{N}^{\circ} 2$.

Kolb, R., 2000: La bonne foi en droit international public. Contribution à l'etude des príncipes généraux de droit, París, Presses Universitaires de France.

Llanos, H., 2009: Teoría y Práctica del Derecho Internacional Público. Introducción y Fuentes. Tomo I ( $4^{a}$ edición), Santiago, Editorial Jurídica de Chile.

López Escarcena, S., 2016: “'Jurisdicción universal protectora de los derechos humanos? El caso de los opositores venezolanos ante la Corte Suprema chilena”, Anuario de Derecho Público 2016 Universidad Diego Portales.

Marie, A., 2018: Le silence de l'Etat comme manifestation de sa volonté, París, Editions A. Pendone.

Martínez, A., 2011: Actos unilaterales, promesa, silencio y nomogénesis en el derecho internacional, Santiago de Compostela, Andavira Editorial.

Miaja de la Muela, A., 1967: "Los actos unilaterales en las relaciones internacionales", Revista Española de Derecho Internacional, vol. 20, $\mathrm{N}^{\circ} 3$.

PecourT, E., 1962: "El principio del estoppel en derecho internacional público", Revista Española de Derecho Internacional, vol. 15, No 1-2. 
Rossel, M., 2007: "Los actos unilaterales como fuentes del derecho internacional contemporáneo, XXXVII Jornadas Chilenas de Derecho Público, vol. II.

SiCAULT, J., 1979: "Du caractère obligatoire des engagements unilatéraux en droit international public", Revue Générale de Droit International Public, vol. 83, N³.

Thirlway, H., 2014: The Sources of International Law, Oxford, Oxford University Press.

Torres, M., 2010: Los actos unilaterales de los Estados, Madrid, Tecnos.

VARGas, E., 2017: Derecho Internacional Público (2a edición actualizada), Santiago, El Jurista.

Documentos de órganos internacionales

CDI, "Yearbook of International Law Commission 1950, Vol. II”, A/CN.4/SER.A/1950/Add. 1, 9.4. 1957.

CDI, "Primer informe sobre los actos unilaterales de los Estados del Sr. Víctor Rodríguez Cedeño, Relator Especial”, A/CN.4/486, 5.3.1998.

CDI, "Anuario Comisión de Derecho Internacional 1998, Vol. I", A/CN.4/SER.A/1998.

AG, "Principios rectores aplicables a las declaraciones unilaterales de los Estados capaces de crear obligaciones jurídicas", A/CN.4/569, 6.4.2006.

\section{Jurisprudencia}

CPJI, Dinamarca con Noruega, 5.10.1933.

CIJ, Reino Unido con Noruega, 18.12.1951.

CIJ, Francia con Reino Unido, 17.11.1953.

CIJ, Honduras con Nicaragua, 18.11.1960.

CIJ, Camboya con Tailandia, 15.6.1962.

CIJ, Australia con Francia, 20.12.1974.

CIJ, Nueva Zelanda con Francia, 20.12. 1974.

CIJ, Declaración del juez Federico de Castro Australia con Francia, 20.12.1974.

CIJ, Canadá con Estados Unidos de Norteamérica, 12.10.1984.

CIJ, Decisión sobre excepción preliminar Nicaragua con Estados Unidos de Norteamérica, 26.11.1984.

CIJ, Nicaragua con Estados Unidos de Norteamérica, 27.6.1986.

CIJ, Burkina Faso con República de Mali, 22.12.1986.

CIJ, Decisión sobre excepción preliminar República Democrática del Congo con Ruanda, 3.2.2006.

CIJ, Bolivia con Chile, 1.10.2018.

CS, 18.11.2015, rol No 17.393. 
